\title{
PENGUATAN UMKM MELALUI PELATIHAN BLOG
}

\author{
Risnal Diansyah*, Syahril , Aryanto, Edo Arribe, Doni Winarso \\ Prodi Sistem Informasi Fakultas Ilmu Komputer, \\ Universitas Muhammadiyah Riau \\ *Email: risnal@umri.ac.id
}

\begin{abstract}
Abstrak
Perkembangan teknologi informasi sudah dirasakan oleh berbagai lapisan masyarakat. Salah satu pemanfaatan teknologi informasi adalah merubah pola bisnis konvensional menjadi bisnis online. Provinsi riau pada umumnya, dan kota pekanbaru pada khususnya, perkembangan Usaha Mikro, Kecil dan Menengah (UMKM) cukup signifikan. Agar dapat bertahan atau memperluas usahanya, pelaku UMKM di kota pekanbaru harus dapat mengikuti perubahan zaman. Salah satunya adalah pemanfaatan teknologi informasi untuk mendukung usaha. Pada kenyataannya, saat ini banyak dari pelaku UMKM, khususnya di kota pekanbaru yang masih asing dengan teknologi informasi. Melalui caturdharma perguruan tinggi, dosen yang ada di prodi SI memiliki tanggungjawab kepada masyarakat untuk pemanfaatan teknologi informasi. salah satu caturdharma tersebut adalah melakukan kegiatan pengabdian kepada masyarakat. Dalam kegiatan ini, program pengabdian kepada masyarakat dosen prodi SI adalah mentransformasikan teknologi informasi berupa pemanfaatan email dan blog bagi pelaku UMKM. Adapun kelompok masyarakat yang menjadi mitra pengabdian adalah warga $R T 03 \mathrm{RW} 01$ Kelurahan Tangkerang Utara Kota Pekanbaru. Hasil dari kegiatan ini adalah peningkatan pengetahuan warga dalam membuat email dan blog. Harapannya adalah, setelah kegiatan ini warga dapat memnfaatkan email dan blog sebagai media untuk peningkatan usaha.
\end{abstract}

Kata kunci: Teknologi Informasi, UMKM, email, Blog.

\section{PENDAHULUAN}

Teknologi informasi saat ini sudah menjadi sebuah kebutuhan yang sangat berarti diberbagai sendi kehidupan [1]. Bahkan teknologi informasi telah berhasil mengubah beberapa cara seseorang maupun organisasi dalam menjalankan aktivitas sehari-harinya, terlebih setelah terbukanya jaringan global dunia yang menghubungkan antar sebuah komputer dengan komputer lainnya atau disebut dengan internet. Jaringan ini telah sukses mengubah cara berkomunikasi mengekspresikan diri, atau mengubah cara memasarkan sebuah produk dalam dunia perdagangan.

Dunia pendidikan sebagai pusat berkembangnya IPTEK dan penghasil SDM yang berkualitas tentulah sangat menyambut baik kehadiran teknologi informasi yang semakin canggih ini [3] . Namun kendala yang dihadapi adalah kita masih belum dapat mengoptimalkan ketersediaan fasilitas dan teknologi yang ada karena kurangnya ketrampilan dan pengetahuan tentang aplikasi internet.

Online marketing adalah alternatif usaha yang dilakukan untuk melakukan pemasaran suatu produk 
ISSN : 2550-0198

atau jasa pada era global ini, tentunya melalui atau menggunakan media internet [5]. Perusahaan maupun individu yang hendak ikut mempromosikan perusahaan yang bekerja sama dengan Google dalam harus memiliki web site atau blog. Google saat ini memiliki program blogger yang gratisan. Siapapun yang berminat boleh melamar sebagai patner kerja dari Google. Di samping dengan blog gratisan, web site komersial dapat juga digunakan sebagai media untuk program Google AdSense. Namun, agar bisa diterima membutuhkan pengetahuan tentang kriteria standar yang ditetapkan oleh pihak Google untuk dapat menerima para pelamar program Google AdSense. Ada dua persayaratan yang paling penting web site yang akan didaftarkan Google AdSense adalah: (1) web site atau blog tidak berisi pornografi dan narkoba, (2) web site atau blog tidak boleh digunakan mengiklankan perusahaan selain memasang iklan yang diberikan oleh Google jika sudah diterima menjadi peserta Google AdSense.

Menyikapi uraian di atas dan dalam rangka pengabdian masyarakat, maka dosen prodi Sistem Informasi, Universitas Muhammadiyah Riau berinisiatif memberikan Pelatihan Pemanfaatan web blog sebagai media informasi, publikasi, dan promosi bagi UMKM yang ada di Kota Pekanbaru, dengan tema Pemanfaatan Umkm Melalui Pelatihan Blog Di Lingkungan Rt 03 Rw 01 Kelurahan Tangkerang Utara Kota Pekanbaru. Kegiatan ini diharapkan mampu membantu UMKM yang ada di kota pekanbaru dalam memanfaatkan blog untuk memperluas bisnis.

\section{METODE PENGABDIAN}

\section{Waktu Dan Tempat Pelaksanaan}

Kegiatan ini dilaksanakan di RT 03 RW 01 Kelurahan Tangkerang Utara Kota Pekanbaru pada Bulan Agustus 2017. Peserta yang terlibat sebanyak 18 orang yang merupakan warga setempat yang memiliki usaha.

\section{Metode Pelaksanaan Kegiatan}

Metode kegiatan pengabdian dilakukan dengan ceramah, praktik dan diskusi. Kegiatan tersebut dapat dilihat pada table berikut ini

Tabel 1. Pelaksanaan Kegiatan

\begin{tabular}{|c|c|c|}
\hline No & Kegiatan & Materi \\
\hline 1. & Pembukaan & $\begin{array}{l}\text { - Sambutan ketua } \\
\text { RT } \\
\text { - Sambutan } \\
\text { Ketua Prodi } \\
\text { - Pembukaan } \\
\text { secara resmi } \\
\text { kegiatan } \\
\text { pengabdian }\end{array}$ \\
\hline 2. & $\begin{array}{l}\text { Diskusi } \\
\text { Kebutuhan } \\
\text { warga }\end{array}$ & $\begin{array}{l}\text { - Teknologi } \\
\text { informasi dan } \\
\text { pemanfaatannya } \\
\text { bagi masyarakat }\end{array}$ \\
\hline 3. & $\begin{array}{l}\text { Seminar } \\
\text { teknologi } \\
\text { informasi }\end{array}$ & $\begin{array}{l}\text { - Pemanfaatan } \\
\text { email } \\
\text { - Pemanfaatan } \\
\text { blog }\end{array}$ \\
\hline 4. & $\begin{array}{l}\text { Praktik } \\
\text { teknologi } \\
\text { informasi }\end{array}$ & $\begin{array}{l}\text { - } \text { Praktik } \\
\text { pembuatan } \\
\text { email } \\
\text { - Praktik } \\
\text { pembuatan } \\
\text { blog. }\end{array}$ \\
\hline
\end{tabular}

\section{Instrumen Kegiatan}

Instrument yang digunakan selama kegiatan berangsung adalah, infocus yang digunakan untuk menampilkan slide presentasi, laptop, jaringan internet, situs media social. 


\section{HASIL DAN PEMBAHASAN}

Pengabdian masyarakat yang telah direncanakan sebelumnya telah dilaksanakan melalui kegiatan diskusi, seminar, dan praktik. Pertama, Diskusi merupakan kegiatan musyawarah yang antara dosen prodi SI dengan warga RT 03. Dalam hasil diskusi tersebut didapatkan poin-poin sebagai berikut.

1. RT 03 secara terbuka akan menerima segala bentuk pengabdian yang akan dilakukan di lingkungan RT 03, terutama hal-hal yang berkaitan dengan peningkatan dan penguatan ekonomi warga.

2. Ada keinginan dari ketua RT 03 untuk menjalin kerjasama dengan UMRI dalam pelaksanaan kegiatan pengabdian masyarakat, hal ini bisa dalam bentuk RT Binaan.

3. Prodi SI akan melakasanakan pengabdian untuk pemanfaatan teknologi informasi sebagai media penguatan UMKM. Kedepannya Prodi SI dapat bekerjasama dengan prodi lainnya dalam hal cek kesehatan, kajian bulanan, dan penyuluhan etika.

Kedua, seminar merupakan kegiatan penyampaiakn materi oleh salah satu dosen Sistem Informasi berupa transformasi pengetahuan mengenai email dan blog. Kegiatan ini dilakukan sekitar 1 jam yang terdiri dari 2 sesi. Sesi pertama penyampaian materi oleh narasumber dan kedua sesi tanya jawab. Ketiga, praktik merupakan kegiatan pembuatan email dan blog yang langsung dilakukan oleh pelaku UMKM di lingkungan RT 03.

Semua kegiatan pengabdian ini berjalan dengan lancar sesuai dengan perencanaan yang telah dibuat. Kegiatan ini dihadiri oleh sekitar 25 orang secara keseluruhan, akan tetapi yang mengikuti kegiatan untuk praktik pembuatan email dan blog hanya diikuti oleh 16 orang (Daftar hadir terlampir). Acara pembukaan kegiatan ini langsung dihadiri oleh Ketua RT 03 sekaligus memberikan pengarahan kepada warga terkait kegiatan pengabdian ini.

\section{Email}

Email merupakan salah satu fasilitas yang ada di internet untuk keperluan surat menyurat. Sama seperti kegiatan surat-menyurat melalui jasa pos, email mampu menangani jasa pengiriman berita dan dokumen dalam bentuk data elektronik (file), termasuk jasa e-card (kartu ucapan elektronik). Electronic mail (Surat elektronik), sering disebut e-mail atau email, merupakan metode Store and Forward dari menulis, mengirim, menerima dan menyimpan surat melalui sebuah sistem komunikasi elektronik.

Konsep Email adalah seperti mengirim surat dengan pos biasa, dimana si pengirim mengirimkan surat ke kantor pos dengan dibubuhi alamat penerima yang akan dituju. Dari Kantor Pos tersebut akan disampaikan ke Kantor Pos yang terdekat dengan alamat yang dituju sehingga akhirnya sampai ke alamat surat tersebut. Pada akhirnya, si penerima surat hanya membuka kotak pos-nya saja yang ada didepan rumah. 
ISSN : 2550-0198

Dengan Email data dikirim secara elektronik sehingga sampai di tujuan dengan sangat cepat. Email juga dapat mengirim file-file berupa program, gambar, graphik dan lain sebagainya. Dengan email juga dapat mengirim ke lebih dari satu orang sekaligus pada saat bersamaan.

Bentuk umum sebuah alamat email adalah sebagai berikut: namapengguna@situs.com

- namapengguna : identitas alamat pemilik email (login nama atau user id).

- @ : dibaca at (artinya di).

- situs.com : alamat situs penyedia fasilitas email.

Sebuah alamat surat (mail address) adalah gabungan dari nama dan alamat. Dalam Internet Mail hal ini didifinisikan dengan nama user dan alamat host.

\section{Blog}

Menurut Mokoginta [8] Blog adalah kependekan dari Weblog, istilah yang pertama kali digunakan oleh Jorn Barger pada bulan Desember 1997. Jorn Barger (www.robotwisdom.com) menggunakan istilah Weblog untuk menyebut kelompok website pribadi yang selalu diupdate secara kontinyu dan berisi link-link ke website lain yang mereka anggap menarik disertai dengan komentar-komentar mereka sendiri.

Dalam tulisannya, Kristiyanti [10] menjelaskan bahwa blog dapat berfungsi sebagai sumber belajar. Sumber belajar adalah apa saja (orang, bahan, alat, teknik, lingkungan) yang mendukung serta memungkinkan memberikan kemudahan dan kelancaran terjadinya belajar, serta memungkinkan terjadinya interaksi antara pebelajar dengan sumber belajar tersebut. Sumber belajar memiliki fungsi sebagai berikut [10]:

- Meningkatkan produktivitas pembelajaran dengan jalan: (a) mempercepat laju belajar dan membantu pengajar untuk menggunakan waktu secara lebih baik dan (b) mengurangi beban pengajar dalam menyajikan informasi, sehingga dapat lebih banyak membina dan mengembangkan gairah.

- Memberikan kemungkinan pembelajaran yang sifatnya lebih individual, dengan cara: (a) mengurangi kontrol pengajar yang kaku dan tradisional; dan (b) memberikan kesempatan bagi pebelajar untuk berkembang sesuai dengan kemampuannnya.

- Memberikan dasar yang lebih ilmiah terhadap pembelajaran dengan cara: (a) perancangan program pembelajaran yang lebih sistematis; dan pengembangan bahan pengajaran yang dilandasi oleh penelitian.

- Lebih memantapkan pembelajaran, dengan jalan: (a) meningkatkan kemampuan sumber belajar; (b) penyajian informasi dan bahan secara lebih kongkrit.

- Memungkinkan belajar secara seketika, yaitu: (a) mengurangi kesenjangan antara pembelajaran yang bersifat verbal dan abstrak dengan realitas yang sifatnya kongkrit; (b) memberikan pengetahuan yang sifatnya langsung. 


\section{Pelaksanaan Kegiatan}

Kegiatan yang diikuti oleh warga RT 03 RW 01 Kelurahan Tangkerang Utara Kota Pekanbaru. Hal ini dilihat dari antusiasme peserta dalam mengikuti kegiatan dari awal hingga akhir. Banyak masukan yang didapat dari diskusi yang dilaksanakan.

Kegiatan ini dilakukan dengan mengambil narasumber dosen dari prodi System Informasi Fakultas Ilmu Komputer Universitas Muhammadiyah Riau. Pada sesi pertama Pembukaan dilakukan oleh ketua program studi, Syahril., M.Kom. kegiatan selanjutnya adalah sesi diskusi yang dipimpin oleh Edo Arribe., MMSI.sesi selanjutnya adalah praktik pembuatan email dan blog, yang menjadi instruktur pada kegiatan ini adalah Ariyanto, SE., MIT., Ak dan Syahril., M.Kom. adapun ketua pengabdian ini adalah Risnal Diasnyah, MTI. Penanggungjawab seluruh materi adalah Doni Winarso, M.Kom.

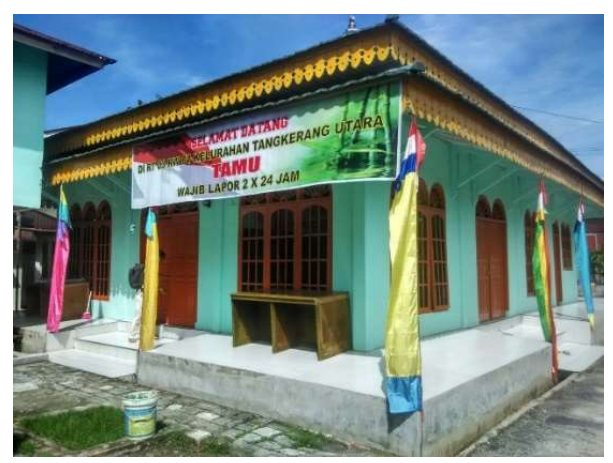

Gambar 1. Lokasi Pembukaan Kegiatan pengabdian

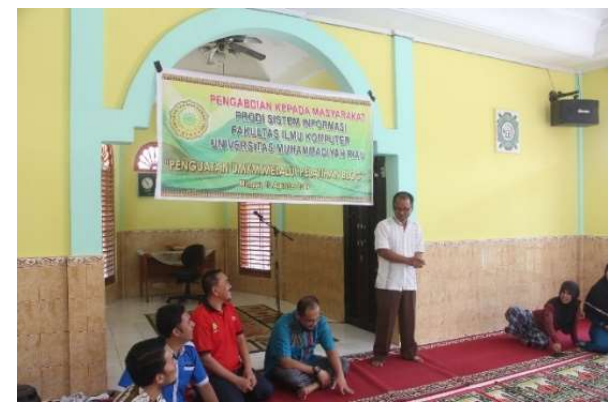

Gambar 2. Sambutan oleh ketua RT 03

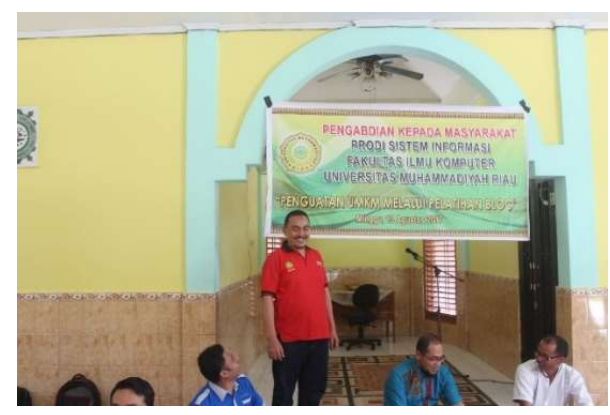

Gambar 3. Sambutan dan Pembukaan secara resmi kegiatan pengabdian oleh kaprodi SI

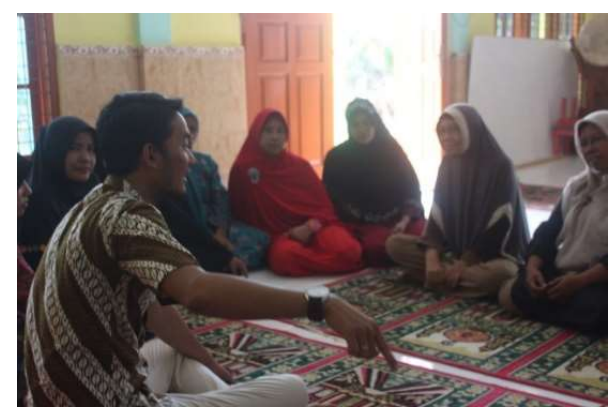

Gambar 4. Sesi Diskusi yang di pandu oleh Edo Arribe, MMSI.

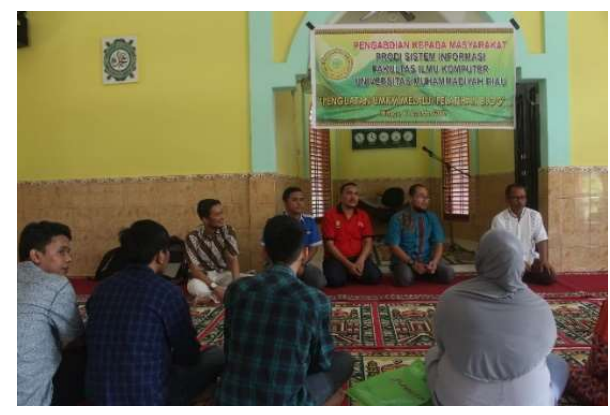

Gambar 5. Suasana sesi seminar 
ISSN : 2550-0198

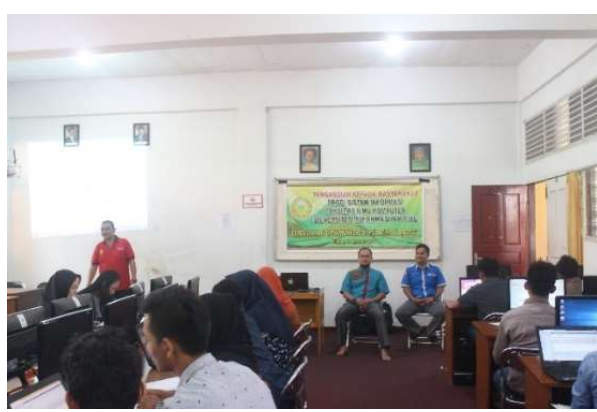

Gambar 6. Sesi praktikum

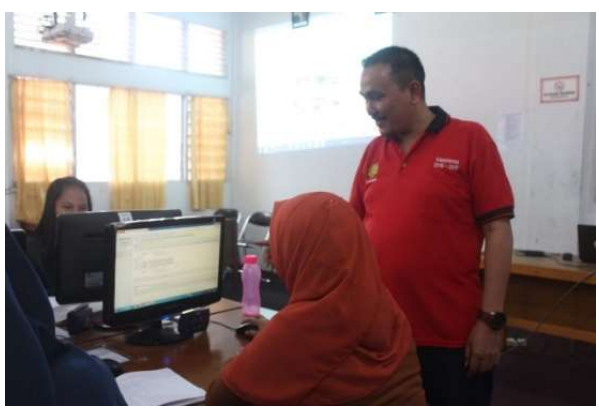

Gambar 7. Peserta dibimbing langsung instruktur

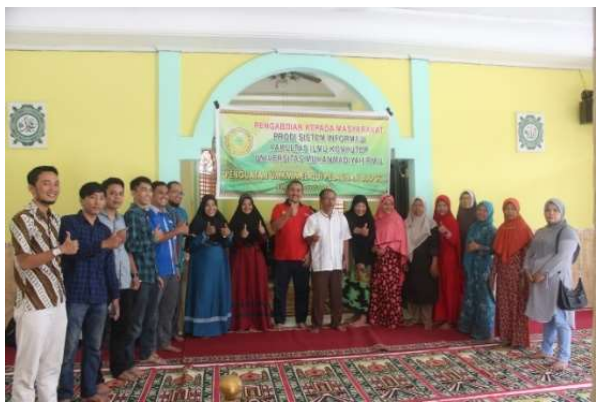

Gambar 8. Foto Bersama

\section{SIMPULAN}

Kegiatan pengabdian telah dilakukan di RT 03, dihasilkan bahwa warga dapat memanfaatkan email dan blog sebagai media penguatan usaha.

Kegiatan pengabdian kepada masyarakat yang telah kami laksanakan dapat disimpulkan sebagai berikut :

- Kegiatan ini berjalan dengan lancar, terlaksana sesuai dengan tujuan dan rencana yang telah dibuat sebelumnya.

- Kegiatan ini mendapat sambutan yang baik dari para peserta.

- Kegiatan ini dapat memberikan tambahan pengetahuan bagi para warga terutama pelaku UMKM di Lingkungan RT 03 RW 01 Kelurahan Tangkerang Utara Kota Pekanbaru.

\section{UCAPAN TERIMAKASIH}

Ucapan terimakasih disampaikan kepada

- Lembaga Penelitian dan Pengabdian Masyarakat (LPPM ) Universitas Muhammadiyah Riau (UMRI) yang telah memberikan dukungan berupa biaya dan motivasi.

- HIMA Prodi Sistem Informasi yang telah membantu kegiatan pengabdian ini

- RT 03 RW 01 Kelurahan Tangkerang Tengah Kota Pekanbaru yang telah memfasilitasi kegiatan pengabdian ini.

- Seluruh Peserta kegiatan yang merupakan pelaku UMKM yang begitu antusias dalam mengikuti kegiatan ini.

\section{DAFTAR PUSTAKA}

[1] A. Nugroho, E-Commerce Memahami Perdagangan Modern di Dunia Maya. BANDUNG: Informatika, 2006.

[2] M. Sumolang, "Journal Volume II. No. 4. Tahun 2013," vol. II, no. 4, 2013. 
[3] T. Tharom, Mengenal Teknologi Informasi. Jakarta: Elex Media Komputindo Kelompok Gramedia, 2002.

[4] Rijal, M. Basur "Analisis Akad Google Adsense perspektif Hukum Islam" Yogyakarta, 2016.

[5] Setiawati, Ira, Peran Media Sosial sebagai Upaya Pemasaran Bisnis Online (Perspektif Kualitatif). STMIK HIMSYA, 2017.

[6] Nayoan, Nova, JON FEKON Volume 3 Nomor 1 (Februari) tahun 2016.

[7] N. Arifia, "Email," Gunadharma, 1 Juni 2010. [Online]. Available: http://narendro.staff.gunadarma .ac.id/Downloads/folder/0.2 . [Accessed 138 2017].

[8] D.Mokoginta, "IlmuKomputer.com," 2008. [Online]. Available: http://ilmukomputer.org/wpcontent/uploads/2009/01/deydi -blog.pdf. [Accessed $13 \quad 8$ 2017].

[9] M. H. Santosa, "Pemanfaatan Blog (Jurnal Online) dalam Pembelajaran Menulis," Universitas Pendidikan Ganesha, Bali, 2015.

[10] M. Kristiyanti, "Blog Sebagai Alternatif Media Pembelajaran," Majalah Ilmiah Informatika, vol. 2, no. No. 2, pp. 33-45, 2011. 